
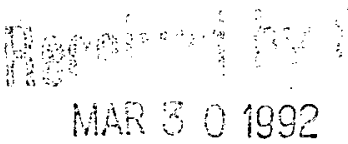

\title{
TENSOR CONTROLLED-SOURCE AUDIOMAGNETOTELLURIC SURVEY OVER THE SULPHUR SPRINGS THERMAL AREA, VALLES CALDERA
}

\author{
Annual Report To
}

Department of Energy

Office of Basic Energy Sciences

Division of Geosciences

\section{by}

Philip E. Wannamaker*

October, 1991

\section{DISCLAIMER}

This report was prepared as an account of work sponsored by an agency of the United States Government. Neither the United States Government nor any agency thereof, nor any of their employees, makes any warranty, express or implied, or assumes any legal liability or responsibility for the accuracy, completeness, or usefulness of any information, apparatus, product, or process disclosed, or represents that its use would not infringe privately owned rights. Reference herein to any specific commercial product, process, or service by trade name, trademark, manufacturer, or otherwise does not necessarily constitute or imply its endorsement, recommendation, or favoring by the United States Government or any agency thereof. The views and opinions of authors expressed herein do not necessarily state or reflect those of the United States Government or any agency thereof.

*Earth Science Laboratory

University of Utah Research Institute

391 Chipeta Way, Suite C

Salt Lake City, Utah 84108-1295 


\section{DISCLAIMER}

This report was prepared as an account of work sponsored by an agency of the United States Government. Neither the United States Government nor any agency Thereof, nor any of their employees, makes any warranty, express or implied, or assumes any legal liability or responsibility for the accuracy, completeness, or usefulness of any information, apparatus, product, or process disclosed, or represents that its use would not infringe privately owned rights. Reference herein to any specific commercial product, process, or service by trade name, trademark, manufacturer, or otherwise does not necessarily constitute or imply its endorsement, recommendation, or favoring by the United States Government or any agency thereof. The views and opinions of authors expressed herein do not necessarily state or reflect those of the United States Government or any agency thereof. 


\section{DISCLAIMER}

Portions of this document may be illegible in electronic image products. Images are produced from the best available original document. 


\section{TABLE OF CONTENTS}

Summary $\quad$.............................................................. i

Introduction $\quad$............................................................ 1

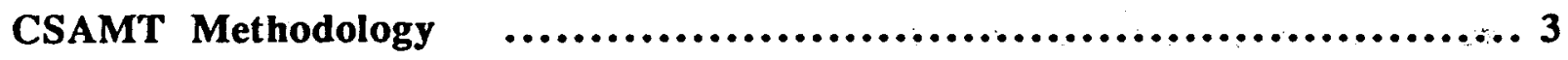

Geological Setting and Prior Resistivity Surveys $\ldots . \ldots \ldots \ldots \ldots \ldots \ldots \ldots \ldots \ldots . . \ldots 6$

Geologic Setting of Valles Caldera and Sulphur Springs

Resistivity Determinants at Sulphur Springs

Prior Electrical Resistivity Surveys at Valles Caldera

Tensor CSAMT Data From the Sulphur Springs Area $\ldots . \ldots \ldots \ldots \ldots \ldots \ldots \ldots \ldots . . . .11$

Tensor CSAMT Data Acquisition Procedure

Observed Tensor CSAMT Results

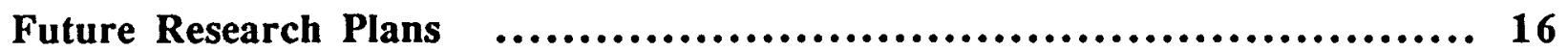

Construction of Resistivity Models

Controlled-Source Field Geometries at Sulphur Springs

Static Versus Tensor CSAMT Quantities

Controls on CSAMT Near-Field Behavior

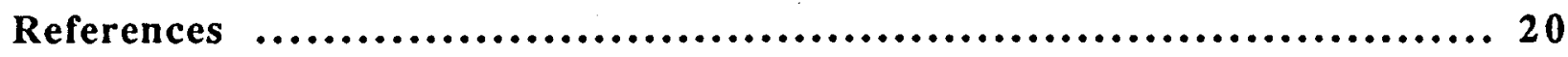

Figures $\quad$........................................................ 24 


\section{SUMMARY}

Under support to date from DOE/OBES, we have recently completed an extensive tensor CSAMT survey of the Sulphur Springs geothermal area, Valles Caldera, New Mexico. This survey, consisting of 45 high-quality soundings acquired in continuous-profiling mode, has been funded in support of CSDP drillholes VC-2A and VC-2B. Two independent transmitter bipoles were energized for tensor measurements using a $30 \mathrm{KW}$ generator placed approximately $13 \mathrm{~km}$ south of the VC-2B wellhead. These current bipoles gave source fields over the receiver sites which were substantially independent in polarization and provided well-resolved tensor elements. The soundings in the Sulphur Springs area were arranged in four profiles to cross major structural features. At each receiver, two orthogonal electric and three orthogonal magnetic field components were acquired in accordance with tensor principles. The electric bipoles parallel to each profile were deployed contiguously to ensure against spatial aliasing of the impedance response corresponding to current flow across structural trends. The frequency range of acquisition was $4096 \mathrm{~Hz}$ down to $1 \mathrm{~Hz}$ for the central line, but only down to $4 \mathrm{~Hz}$ for most of the other lines. Data quality is high overall and is established by repeatability of measurements. Agreement between the CSAMT and available natural field MT data is very good over almost all the period range of overlap indicating that we are free of calibration problems and that far-field results are generally being obtained. Near-field effects in the CSAMT are apparent at 1 to $2 \mathrm{~Hz}$, however, which is the very bottom of our frequency range. Derivation of model resistivity cross sections from our data and their correlation with structure and geochemistry are principal components of the OBES award. However, Sulphur Springs also can serve as a natural testbed of traditional assumptions and methods of CSAMT with quantification through rigorous model analysis. Issues here include stability and accuracy of scalar versus tensor estimates, theoretical versus observed field patterns over the survey area, and controls on near-field effects using CSAMT and natural field data both inside and outside the caldera. 


\section{INTRODUCTION}

Electrical resistivity is being recognized increasingly as a unique window on earth processes and resources (Wannamaker and Hohmann, 1991). One of the most widely applied approaches for resolving resistivity structure is estimation of the plane-wave EM impedance of the earth ,e.g.; magnetotellurics (MT) and related methods. In this approach, the source EM fields do not decay geometrically with depth, which tends to improve resolution vertically. In addition, measurement of the electric field component also improves resolution, especially laterally, provided it is properly interpreted. Finally, the state of the art in multi-dimensional EM response modeling and inversion is relatively well advanced for plane-wave methods.

For exploration scales limited to the upper $2 \mathrm{~km}$ or so of the earth (frequencies from one or a few Hertz to perhaps $10 \mathrm{kHz}$ ), it is considered practical to generate planar EM fields using distant artificial current sources. This is the controlled-source audiomagnetotelluric (CSAMT) technique (Goldstein and Strangway, 1975; Zonge and Hughes, 1991); Such an approach has been extensively used for exploration problems in geothermal (e.g., Sandberg and Hohmann, 1982; Bartel and Jacobson, 1987), precious metal (Corbett, 1991; Wilds and MacInnes, 1991), and hydrocarbon (Hughes and Carlson, 1987; Ostrander, 1990) environments. Many other case histories including sulfide exploration, mapping of brine plumes, and geotechnical applications are reviewed by Zonge and Hughes (1991).

One major difference between the natural-field MT and the CSAMT procedures is the muchsimplified, scalar approach typical of the latter measurement. Tensor data has been considered essential for MT for over thirty years now due to recognized inhomogeneity in the earth and temporal variations in the natural field polarizations. Scalar measurements have been taken for CSAMT due often to cost considerations and perhaps to the assumption that responses from the upper 1-2 km are less inhomogeneous than crustal-scale responses and that dense coverage by scalar measurements should be sufficient to constrain lateral structure. Since the reputation of a geophysical method depends on its accuracy and reliability, a detailed comparison of the rigorous tensor approach with the more economical scalar method is very important. However, such a comparison has not been published, to our knowledge. A second difference between MT and CSAMT is the fundamental low-frequency limit encountered by the latter beyond which the assumption of plane-wave geometry is not met. This limit depends upon separation of source and receivers and, in often complicated ways, upon the resistivity structure hosting both (Zonge and Hughes, 1991). There has been limited computer simulation of transmitter effects with inhomogeneous structure in CSAMT (Sandberg and Hohmann, 1982; Boschetto and Hohmann, 1991) but not a detailed analysis incorporating both field data and theory. 
We believe we are in a unique position to advance understanding of the CSAMT method through the work proposed herein. First, we have recently completed an extensive tensor CSAMT survey of the Sulphur Springs geothermal area, Valles Caldera, New Mexico. This survey, consisting of 45 high-quality sites acquired in continuous-profiling mode, has been funded by DOE/OBES in support of CSDP drillholes VC-2A and VC-2B (Heiken et al., 1990). Second, researchers at UURI and the Department of Geology and Geophysics (lead by G. W. Hohmann) are world leaders in the modeling and interpretation of inhomogeneous EM responses, both planewave and finite source. Derivation of model resistivity cross sections from our data set and their correlation with structure and geochemistry are components of the original OBES award and this effort is ongoing. However, Sulphur Springs also can serve as a natural testbed of traditional assumptions and methods of CSAMT with quantification through rigorous model analysis. A continuation proposal to OBES on this topic is pending.

It is our purpose, therefore, to also incorporate a detailed resistivity model of the Sulphur Springs area from our measurements into a general and simplified model of the caldera resistivity as a whole, and also derive an estimate of the approximately layered resistivity host to the caldera. In terms of both host and generalized 3-D caldera structure, we intend to compare theoretical and observed electric and magnetic field geometries as a function of frequency over the survey area. Subsequently, scalar, vector and tensor CSAMT data may be contrasted over the area and discrepancies explained in relation to inhomogeneity (through the tensor elements) and EM field orientation. Controls on near-field transmitter effects should be quantified through 3-D simulations, to show whether they depend mainly on local structure, the caldera host, or a combination of both. Conclusions of such computer simulations can be verified by existing natural field MT soundings within and outside the caldera. This latter work emphasizing tensor methodology in a complicated environment, forms a logical complement to the geologic interpretation of resistivity in the Sulphur Springs vicinity, an interpretation well-constrained by extensive surface mapping, core-drilling, and geochemistry. 


\section{CSAMT METHODOLOGY .}

Schematics of the field layout for both scalar and tensor CSAMT surveys are given in Figure 1 (Zonge and Hughes, 1991). For the scalar method, the very popular broadside deployment is shown (Figure 1a). Here, single electric and magnetic field sensors (i.e., dipole and coil) at a receiver site measure fields from a single current bipole displaced from but parallel to the electric receiver. Scalar impedances, apparent resistivities, and impedance phases are obtained from simple field ratios. The broadside source displacement from the receiver need not be quite as large. as an end-on source displacement (three skin depths in the most representative medium for the former versus five skin depths for the latter, Sandberg and Hohmann, 1982; Zonge and Hughes; 1991) and typically yields twice the signal strength for a given displacement as the end-on deployment (op. cit.). Often, a contiguous array of electric field bipoles is oriented across presumed geologic strike with a magnetic field sensor placed intermittently along the profile. This layout has been applied widely to structural mapping in precious metal and hydrocarbon environments because the electric field thus measured is more sensitive to fault displacements of conductive alluvium and the 2-D assumption is relatively valid for this geometry (the transverse magnetic or TM mode; Wannamaker et al., 1984: Vozoff, 1986). As profiling data is acquired, the source bipole would 'leap-frog' along to ensure good signal coupling with the receiver sensors. Good signal typically is available in a $90^{\circ}$ wedge subtending broadside from the source, outside of which the fields are too oblique to the measurement axes to obtain reliable data (Sandberg and Hohmann, 1982; Zonge and Hughes, 1991).

For the tensor CSAMT method, five EM field components $\left(\mathrm{E}_{\mathbf{x}}, \mathrm{E}_{\mathbf{y}}, \mathrm{H}_{\mathrm{x}}, \mathrm{H}_{\mathbf{y}}, \mathrm{H}_{\mathrm{z}}\right)$ are measured for two independent polarizations of source current bipole (i.e., ten fields in all at each site, Figure 1b). Plane-wave impedances, apparent resistivities and impedance phases are not defined by simple field ratios as in the scalar approach, but instead by solution of a series of $2 \times 2$ matrix equations determined from the fields due to the two sources. The procedure in fact is identical to that used in computer simulation of tensor impedances over multidimensional models (e.g., Wannamaker et al., 1984). For example, the solutions for the off-diagonal impedance elements in terms of the measured fields are

$$
\mathrm{Z}_{\mathrm{xy}}=\frac{\mathrm{E}_{\mathrm{x}}^{2} \mathrm{H}_{\mathrm{x}}^{1}-\mathrm{E}_{\mathrm{x}}^{1} \mathrm{H}_{\mathrm{x}}^{2}}{\mathrm{H}_{\mathrm{x}}^{1} \mathrm{H}_{\mathrm{y}}^{2}-\mathrm{H}_{\mathrm{x}}^{2} \mathrm{H}_{\mathrm{y}}^{1}}
$$

and

$$
Z_{y x}=\frac{E_{y}^{2} H_{y}^{1}-E_{y}^{1} H_{y}^{2}}{H_{x}^{1} H_{y}^{2}-H_{x}^{2} H_{y}^{1}}
$$


where superscripts 1 and 2 refer to the source bipole number. As is the case for numerical simulation, it is not necessary that all field components be strongly excited for both source polarizations but instead that each component be excited by at least one source (c.f., Zonge and Hughes, 1991). It is obvious that tensor data is considerably more time-consuming to acquire than scalar data, but the tensor response has the great advantage that it is unambiguous regardless of the dimensionality of the field environment.

A collection mode intermediate between scalar and tensor is the vector CSAMT setup (Zonge and Hughes, 1991). Here, all four horizontal fields are also measured (plus $\mathrm{Hz}$ if desired), but only one source bipole is energized. This allows construction of the total field vectors ( $E$ and $H)$ at the receiver regardless of its orientation. Vector measurements thus can provide two orthogonal scalar impedances, or else one impedance based on the total (i.e., best-coupled) fields.

Scalar and tensor CSAMT quantities can be contrasted by examining either row of the $2 \times 2$ tensor impedance. For $\mathrm{E}_{\mathrm{y}}$ it is

$$
E_{y}=Z_{y x} H_{x}+Z_{y y} H_{y}
$$

When normalized by $\mathrm{H}_{\mathbf{x}}$ we have

$$
\frac{E_{y}}{H_{x}}=Z_{y x}+Z_{y y} \frac{H_{y}}{H_{x}}
$$

Note that the ratio on the left-hand side is just the scalar yx impedance. It differs from the true tensor impedance $Z_{\mathrm{yx}}$ by the far right-hand term: the product of tensor element $Z_{\mathrm{yy}}$ and the ratio $H_{y} / H_{x}$. If $Z_{y y}$ is essentially zero, or negligible $H y$ is induced by the source bipole, the scalar and tensor quantities will agree well. As $Z_{y y}$ and $H_{y} / H_{x}$ become significant, however, discrepancies can be expected. In fact, for receiver sensors poorly coupled to the source field for the ,e.g., $E_{y^{-}}$ $\mathrm{H}_{\mathrm{x}}$ scalar measurement, $\mathrm{H}_{\mathrm{y}} / \mathrm{H}_{\mathrm{x}}$ may become much greater than one and substantial disagreement between scalar and tensor quantities ensue even though the multidimensionality (i.e., $\mathrm{Z}_{\mathrm{yy}}$ ) may be quite small. This effect should be most likely as one approaches the boundaries of the wedge-like zones of good field coupling noted previously. It may be responsible in large part for transmitter overprint effects (Zonge and Hughes, 1991) such as commonly seen at joins between E-field spreads measured with different broadside transmitters. An example will be presented from the Sulphur Springs area and it is an important part of this proposal to determine how extensive the problem may be in natural environments. 
A different but equally important topic effecting both scalar and tensor CSAMT data is the planewave assumption toward low frequencies. For sources and receivers on a uniform half-space, separations of three to five skin depths at the lowest frequency of interest produce departures from true plane-wave responses of about 5\% or less (Goldstein and Strangway, 1975; Sandberg and Hohmann, 1982). For layered earths, the departures can sometimes be very sensitive functions of the layering and source-receiver separations (Figure 2; Zonge and Hughes, 1991). Limited modeling of 3-D structure below CSAMT transmitters indicates that conductive inhomogeneity there can prolong the far-field assumption to somewhat lower frequencies relative to a half-space, while resistive inhomogeneity has an opposite effect (Boschetto and Hohmann, 1991). Attempts to correct for the transition to the near-field are based upon 1-D earth models (Zonge and Hughes, 1991). Perhaps the most rigorous technique within the 1-D framework is to invert each sounding using the true finite source over a layered earth, and then compute the plane-wave response of the resultant 1-D model. This would assume that inhomogeneous effects are limited in the sense that the effects would be similar for both plane-wave and finite source responses. We have not yet seen a study comparing near-field correction methods using coincident CSAMT and natural-field MT soundings. 


\section{GEOLOGICAL SETTING AND PRIOR RESISTIVITY SURVEYS OF VALLES CALDERA AND SULPHUR SPRINGS}

The Valles caldera complex, centrally located in the extensive Jemez volcanic field, has been the site of groundbreaking studies of resurgent calderas by the U. S. Geological Survey (Smith and Bailey, 1968; Heiken et al., 1990). With support from the Dept. of Energy/Office of Basic Energy Sciences, Continental Scientific Drilling Program (CSDP) core holes VC-2A and VC-2B were completed in the Sulphur Springs area of the western Valles caldera primarily (a) to obtain continuous core through the intracaldera volcanic sequence and its basement rocks for reconstruction of caldera evolution and (b) to help model the prodigious high-temperature hydrothermal system of the Sulphur Springs area of the caldera (Hulen et al., 1988; Hulen and Gardner, 1989; Hulen et al., 1991).

\section{Geologic Setting of Valles Caldera and Sulphur Springs}

The Valles caldera has been an active Quaternary magmatic system related to Miocene-to-present extensional deformation of the Rio Grande Rift and the Jemez lineament (Smith and Bailey, 1968; Aldrich, 1986; Heiken et al., 1990). After initial silicic volcanism some 3-3.5 Ma, eruptions around 1.45 and $1.1 \mathrm{Ma}$ lead to two nearly coincident calderas, the Toledo first and then the Valles. The principal structural grain in the caldera area trends NE, paralleling the recurrent Jemez fault zone, which itself serves as the western boundary to the thickest pyroclastic stratigraphy (Nielson and Hulen, 1984). Sulphur Springs, the area of most active current hydrothermal manifestation, lies west of this fault zone and of the resurgent Redondo dome (Figure 3).

Volcanic stratigraphy lie unconformably on downfaulted Paleozoic sedimentary rocks and Precambrian crystalline basement. The older sediments consist primarily of Madeira Formation limestone under Yeso and Abo Fm redbeds; the latter are on the order of $500 \mathrm{~m}$ thick in the Sulphur Springs area as encountered in corehole VC-2B (Hulen and Gardner, 1989). The overlying Upper Tertiary Santa Fe arkose and variably-welded Lower Tuffs give way upward to two thick, usually densely welded tuffs comprising the Bandelier Formation, identified as the Otowi (lower) and the Tshirege (upper), with a total thickness of from 330 to $630 \mathrm{~m}$ in the western caldera complex (Hulen et al., 1991). Separating these thick ignimbrite units is less than $10 \mathrm{~m}$ of 'sandstones' (including also breccias and pyroclastic surge deposits), which thicken to several tens of meters near the hypothetical Plinian vent area of the Tshirege Tuff just north of Redondo Peak (Hulen et al., 1991). Fracture porosity is abundant in the Bandelier section in VC-2B, but 
relatively rare there in VC-2A (Hulen et al., 1988; Hulen and Gardner, 1989). The highest lithology in the western area includes porous caldera-fill sediments and debris flow. Present also, mainly around the margins of the Sulphur Springs area, are flows of the San Antonio Mountain ring-fracture vent (west of Sulphur Creek Fault) and of Redondo Greek Graben (in the east portions of area). A more detailed map of Sulphur Springs vicinity is given in Figure 4. Volcanic strata total less than $1 \mathrm{~km}$ in thickness in the western caldera complex whereas a column approaching $4 \mathrm{~km}$ is interpreted to lie in the deep east moat of the caldera (Heiken et al., 1990).

Hydrothermal alteration in the Sulphur Springs area has been interpreted to consist of three depth zones: illite/smectite, illite and propyllitic minerals (+- K-feldspar) (Hulen and Nielson, 1986a; Hulen and Gardner, 1989). The upper clay-rich zones are on the order of $250-300 \mathrm{~m}$ thick, extending through the caldera-fill sediments and into the only moderately-welded, highest levels of the Tshirege tuff. Illite abundance decreases dramatically at greater depths with the onset of dense welding of the tuffs, and hydrothermal propyllitization dominates below about $400 \mathrm{~m}$. Alteration at depth appears broadly similar to that in the Redondo Dome area (Hulen and Nielson, 1986b), with the most important controls being the temperature gradient, fluid composition and rock permeability. The latter in turn is correlated with stratigraphy and so alteration assemblages show a near horizontal disposition. However, illite-smectite clays have been preserved in the Paleozoic clastics despite elevated temperatures, presumably due to low permeability (Hulen and Gardner, 1989). Also, the geothermal fluids responsible for alteration in the Sulphur Springs area are interpreted to be distinct to some extent from those of Redondo Creek area (Hulen and Nielson, 1986a; Goff et al., 1988). There are also local zones of intense phyllic alteration associated with major thermal fluid entries (from fractures) in the wells of both areas (Hulen and Nielson, 1986b; Hulen and Gardner, 1989).

\section{Resistivity Determinants at Sulphur Springs}

In the Sulphur Springs geothermal area, the dominant controls on bulk rock resistivity should be electrolytic conduction through rock pores and fractures and along mineral surfaces (especially clays) (Olhoeft, 1981). Electrical conductivity $\sigma_{\mathrm{r}}$ (inverse of resistivity $p_{\mathrm{r}}$ ) of rocks containing relatively conductive fluids is described typically using Archie's Law, which is

$$
\sigma_{\mathrm{r}}=A \sigma_{\mathrm{w}} \phi^{\mathrm{m}}
$$

where $\mathrm{A}$ is a geometric constant, $\sigma_{\mathrm{w}}$ is the pore water conductivity, $\phi$ is rock porosity, and $\mathrm{m}$ is the tortuosity coefficient dependent upon pore geometry. For most rocks and sediments when 
conduction is through intergranular pores, $A=1$ and $m=2$ based on empirical observation. For randomly oriented fractures, $A=2 / 3$ and $m=1$. Because $m=1$ for fractures, they may be effective in reducing bulk resistivity even if they constitute a minority of total porosity.

The total dissolved solids content observed in fluids in the western Valles system lies around $0.1 \mathrm{~N}$ and is primarily $\mathrm{NaCl}$ (Hulen and Nielson, 1986b; J. B. Hulen, pers. comm., 1991). Over the temperature range $20^{\circ} \mathrm{C}$ to $250^{\circ} \mathrm{C}$, the conductivity of such a fluid may vary from 1 to $5 \mathrm{~S} / \mathrm{m}$ (resistivity from 1 to $0.2 \mathrm{ohm}-\mathrm{m}$ ) (Quist and Marshall, 1968). For unconsolidated caldera-fill sediments in the upper $200 \mathrm{~m}$ or so of the section with a porosity on the order of $15 \%$, a representative bulk resistivity may be around $30 \mathrm{ohm}-\mathrm{m}$. For the welded ignimbrite section below with intergranular porosity of only a few percent, resistivities of hundreds of ohm-m may be possible. This would disregard contributions from fracture porosity. Lower resistivities may be expected again in the more porous and permeable Lower Tuffs and arkose, and the still clay-rich redbeds, while high resistivities are presumed typical of the metamorphosed and relatively impermeable carbonates and Precambrian rocks. However, as noted in the next section, high resistivities may not be diagnostic of the carbonates outside the caldera.

Clay minerals can lower rock resistivities substantially by contributing exchangeable cations to the pore solution (e.g., Waxman and Smits, 1968). This effect is strongest for very dilute pore fluids. Measurements by Ward and Sill (1976) on highly altered samples from the Roosevelt Hot Springs thermal area (Ward et al., 1978) with pore fluids near $0.1 \mathrm{~N} \mathrm{NaCl}$ suggested that clays might reduce resistivities of porous sediments by a factor of 2 to 4 . Thus, unconsolidated caldera fill and debris flow in the Sulphur Springs area may show resistivities as low as 10 ohm-m. Below $250-300 \mathrm{~m}$ in the densely welded tuffs and especially in the propyllitic regime, the contribution of clays to reducing resistivity should be much decreased compared to within the shallowest units. Clays are likely to remain important in lowering resistivity in the Paleozoic section. Porosity and the degree and species of clay alteration logged in wells B-8 and VC-2A and VC-2B should provide some calibration of a CSAMT model for the entire survey area.

On the basis of its acid springs and fumaroles, and of steam entries and sub-hydrostatic pressures in wells, Sulphur Springs has been interpreted as the surface expression of a small, vapor-dominated geothermal system (Goff et al., 1985). Vapor-dominated systems are important to the geothermal industry because they may yield dry steam, which is the most economically desireable geothermal resource. A boiling interface to a liquid-dominated regime below is believed to lie at a depth of around $500 \mathrm{~m}$ beneath Sulphur Springs (op. cit.). The electrical conductivity of pure, dry steam is very small, with the conduction of steam-filled rock being due largely to 
condensation and surface conduction along pore walls, a mechanism not yet adequately studied (Olhoeft, 1981). Zohdy et al., (1973) interpreted a high-resistivity steam zone in Yellowstone using dipole-dipole resistivity. Estimating resistivity of the vapor zone at Sulphur Springs has been one of the primary purposes of our CSAMT survey.

\section{Prior Electrical Resistivity Surveys at Valles Caldera}

Direct-current (dc) resistivity soundings for assessment of hot dry rock geothermal resources have been taken and described by Jiracek et al., (1975). These included roving bipole-dipole reconnaissance, shallow Schlumberger soundings and deep dipole-dipole soundings concentrated in the Fenton Hill area (Figure 3). Layered sounding models, constrained by drilling logs, showed a thin $(100 \mathrm{~m})$ section of volcanics of highly variable resistivity over a thick section $(633 \mathrm{~m}$, similar to VC-2B) of Paleozoic sediments, all of the latter showing low resistivity around 15 ohm-m. Crystalline Precambrian basement below $733 \mathrm{~m}$ exhibited high resistivity of hundreds to thousands of ohm-m. A $300 \mathrm{ohm}-\mathrm{m}$ zone $100 \mathrm{~m}$ thick near the upper surface of the basement corresponded to a highly fractured zone with considerable water content (Jiracek et al., 1975).

An extensive review of the upper crustal geology and geophysics of Valles caldera has been given by Wilt and vonder Haar (1986). An averaged resistivity log of the volcanic section near the northern end of Redondo Creek graben shows low resistivities (2-10 ohm-m) in porous and altered sediments of the upper $200 \mathrm{~m}$, but a generally resistive (100-500 ohm-m) Bandelier Tuff section below over $1 \mathrm{~km}$ thick. Low resistivities (10-70 ohm-m) are seen again in the more porous Lower Tuffs and pre-caldera volcanics containing hot saline reservoir fluids (Wilt and vonder Haar, 1986). Resistivity sections derived using telluric and magnetotelluric (MT) profiling showed a lower resistivity volume at a depth near $1 \mathrm{~km}$ roughly coincident with the Redondo Creek graben reservoir zone, and a low resistivity section of thick sediments in the Valle San Antonio moat area to the north. Low resistivities at depths from 1 to $3 \mathrm{~km}$ were interpreted also below a profile from the graben west to Sulphur Creek fault approximately coincident with our CSAMT line N2 (Figure 4). The MT modeling produced generally high resistivity values for the Bandelier Tuff as well (>100 ohm-m) over both MT profiles analyzed. However, we expect some variance between this latter model cross section and those resulting from our data and analysis, stemming primarily from our contiguous data coverage and the multidimensional modeling approach we will take.

Numerous MT soundings for geothermal assessment in Valles caldera were taken by Unocal Geothermal Co. in the early 1980's. The only public domain report of this work is Crecraft et al., 
(1988) but four representative soundings of this suite have been released to us and negotiations continue for more sites. These data will be valuable in constructing an overall resistivity model at upper crustal levels at Valles caldera for model control of our Sulphur Springs data set as well as allowing a thorough analysis of controlled-source effects in the CSAMT method. To these ends also, MT soundings taken by San Diego State University as part of their Summer of Applied Geophysical Experience (SAGE) program (Jiracek et al., 1991) both within and outside the caldera will be very useful. Some of this latter data will be compared to our own shortly. 
TENSOR CSAMT DATA FROM THE

SULPHUR SPRINGS AREA

To extend knowledge of structure and physical state at depth beyond that from surface mapping and drilling, we have been supported by DOE/OBES to carry out a tensor CSAMT survey in the the Sulphur Springs area. This section discusses our experimental approach, describes the quality and characteristics of our data set, and points out details of scalar/tenisor discrepancies and near-field effects germane to our future research.

\section{Tensor CSAMT Data Acquisition Procedure}

Transmitter placement in CSAMT surveys involves a compromise between two competing issues. On the one hand, to obtain planar EM waves, the transmitter-receiver separation should be as great as possible; a doubling of this separation effects a fourfold decrease in the frequency at which near-field effects first appear (Goldstein and Strangway, 1975; Zonge and Hughes, 1991). On the other, however, signal strength varies as the inverse cube of distance (op. cit.) imposing an upper limit on separation determined by telluric and other noise sources. At Valles caldera, our transmitter was a Zonge Engineering and Research Organization model GGT-30 placed approximately $13 \mathrm{~km}$ (8 miles) south of the VC-2B wellhead (Figure 3). As demonstrated shortly, this position appeared to give good signal strength over the Sulphur Springs area while allowing some near-field effect at 1 and $2 \mathrm{~Hz}$, which is at the bottom of our measurement range.

The two independent transmitter bipoles (TX1 and TX2 in Figure 3) for tensor measurements were oriented about $\mathrm{N} 28^{\circ} \mathrm{W}$ and $\mathrm{N} 45^{\circ} \mathrm{E}$ and were just over $2 \mathrm{~km}$ in length each. While not quite $90^{\circ}$ apart, these orientations gave source fields over the receiver sites which were substantially independent in polarization and provided well-resolved tensor elements. Contact with the ground was made by auguring five holes about 2-1/2 feet deep and about 15 feet apart in a star pattern at the end of each bipole ( 20 holes in all). Brass rods and braided cabling provided contact with the earth in each hole, which was filled with unconsolidated soil and ice melt compound and saturated with saline water at least every other day. The 15 foot separation between contact points ensured a nearly parallel circuit of ground resistances and gave a DC impedance of about 40 ohms between endpoints of each transmitter bipole. Consequently, current loads of 20 amps typically were possible except at the highest frequencies (above $1 \mathrm{kHz}$ ) where the inductance of the wire became important (Zonge Engineering Org., pers. comm.). This inductance reduced transmitter currents to as small as 5 amps at $4.1 \mathrm{kHz}$ and prevented usable data at $8.2 \mathrm{kHz}$. 
The soundings in the Sulphur Springs area were arranged in four profiles to cross major structural features (Figure 4). At each receiver, two orthogonal electric and three orthogonal magnetic field components were acquired in accordance with tensor principles as described with Figure 1. The electric bipoles parallel to each profile were deployed contiguously to ensure against spatial aliasing of the impedance response corresponding to current flow across structural trends (EMAP mode; Bostick, 1986; Torres-Verdin and Bostick, 1991). All bipoles normal to each profile and most bipoles along each profile were nominally $250 \mathrm{~m}$ in length. Some bipoles along the profiles near their ends were $500 \mathrm{~m}$ long to extend data coverage efficiently away from coreholes VC-2A and VC-2B. The $\mathrm{x}$-axis is assigned to the northeast direction while the $y$-axis is southeast. The frequency range of acquisition was $4096 \mathrm{~Hz}$ down to $1 \mathrm{~Hz}$ for the central line $\mathrm{N} 1$, but only down to $4 \mathrm{~Hz}$ for most of the other lines. Data to $1 \mathrm{~Hz}$ was taken at selected sites on the other lines for control. We found that fully one-third of the recording time at a site was spent taking the 1 and $2 \mathrm{~Hz}$ results. Fields were recorded on a Zonge Engineering Org. model GDP-16 receiver with data blocks downloaded to an IBM-compatible PC at the end of each working day for final processing. Magnetic field sensors were obtained from Electromagnetic Instruments Inc.; model BF-4 with custom amplifiers capable of acquiring data to $10 \mathrm{kHz}$.

Data quality was established by repeatability of measurements. Typically, five readings at each frequency were taken for each source bipole. Tensor impedance elements were computed for each pair of readings for the two source bipoles using equations (1) and (2), and analogues for the ondiagonal elements. Following removal of occasional outliers, means and error intervals were obtained for the tensor log apparent resistivities and linear phases over each group of readings (Bevington, 1969) in accord with the assumption of Gaussian noise on the output (electric) fields (Gamble et al., 1979; Stodt, 1983). Results were obtained similarly for real and imaginary components of the tensor tipper elements.

\section{Qbserved Tensor CSAMT Results}

An example tensor apparent resistivity sounding is given in Figure 5. This site is immediately east of corehole VC-2B and a natural field MT sounding taken only several tens of meters to the west of it by G. R. Jiracek is included for comparison. The CSAMT data quality appears very good here and this quality is typical of the majority of sites in our survey. Also, the agreement

between the controlled-source and natural field data is very good over almost all the period range of overlap indicating that we are free of calibration problems and that far-field results are generally being obtained. The disagreement between controlled and natural source data is substantially 
apparent at 1 and $2 \mathrm{~Hz}$, especially the impedance phase. Our phases drop to very small values while the apparent resistivities exhibit the transmitter notch behavior exemplified in Figure $2 \mathrm{~b}$ indicative of a conductive layer over a resistive basement. Apparent resistivities of $10 \mathrm{ohm}-\mathrm{m}$ or less are characteristic as the near-field behavior is approached over most sites in the Sulphur Springs survey. However, at $2 \mathrm{~Hz}$ for a half-space of $10 \mathrm{ohm}-\mathrm{m}$ our transmitter would be more than 10 skin depths removed. It suggests that resistivity local to the receiver array may not be the only determining factor in the near-field response and that a more resistive host to the caldera could exist and contribute to this effect. This point will be reconsidered when we show data from outside the caldera.

For the central, longest line N1 of Figure 4, our tensor data are summarized in the form of pseudosections, wherein site position serves as abscissa and log period serves as ordinate for contour plots of log apparent resistivity, impedance phase, and complex tipper elements. (Figures 6 and 7). The lowest apparent resistivities for both the nominal TE (xy-mode) and TM (yx-mode) data occur between the Sulphur Creek and Freelove Canyon faults with shortest-period values just over $10 \mathrm{ohm}-\mathrm{m}$ falling to just under $10 \mathrm{ohm}-\mathrm{m}$ by about $0.1 \mathrm{~s}$ (Figure 6). While detailed modeling is necessary, these values may imply substantial alteration of the Bandelier section compared to values implied by the well log information of Wilt and vonder Haar (1986). East of Freelove Canyon Fault, higher resistivities are evident at periods less than $0.01 \mathrm{~s}$ suggesting relatively unaltered surficial volcanics perhaps including Redondo Creek flows. A substantial thickness of outcropping resistive volcanics is apparent west of Sulphur Creek fault over flows from San Antonio Mountain dome and related ring-fracture vents. A subtle and narrow zone of somewhat greater resistivity than its surroundings seems evident centered below site 1 just west of VC-2B in the period range $0.01-0.2 \mathrm{~s}$. This may represent evidence of a vapor region and will receive close scrutiny in our multi-dimensional modeling of the data set. A similar response, but which starts at shorter periods, is seen on line $\mathbf{S 1}$ just west of corehole VC-2A (not shown) but is not obvious on line N2. At periods greater than $0.25 \mathrm{~s}(\mathrm{f}<4 \mathrm{~Hz})$, the transmitter notch behavior exemplified in Figure 5 can be seen for all stations west of Freelove Canyon fault, but not to the east (Figure 6). This implies a major structural boundary; its interpretation will be most complete if the finite EM source effects, which appear to accentuate the responses, are taken into account.

The vertical magnetic field responses over the survey area are not highly anomalous (Figure 7). For periods under $0.01 \mathrm{~s}$, the values appear to correspond with local topographic slope orientations (e.g., Wannamaker et al., 1986). Between Sulphur Creek and Freelove Canyon faults, a transmitter near-field effect appears to develop for periods greater than $0.25 \mathrm{~s}$. Anomalous behavior west of Sulphur Creek and east of Freelove Canyon faults may be related to subsurface 
structure, but the topographic relief along the profile must be considered in any model. The lack of an appreciable vertical field response due to subsurface structure is valuable information in itself as it relates to limited strike extent of the structure (e.g., Wannamaker et al., 1991).

As discussed with equations (3) and (4), discrepancies between scalar and tensor CSAMT quantities may arise due both to inhomogeneity and to oblique orientation of the source fields. Examples of such differences appear in Figure 8 for two sites on line S1. Site 19 is the fourth from the east end of the line while site 24 is at the far west end. Here are plotted $\rho_{x y}$ and $\rho_{y x}$ in separate panels for comparison with the corresponding scalar quantities resulting from the two transmitter bipoles. At site 19, the scalar results straddle the tensor values and bracket a range from about $0.3-0.5 \mathrm{log}$ units. The two tensor curves are anisotropic by about $0.15-0.2 \mathrm{log}$ units. The total magnetic field here due to bipole 1 lies about $60^{\circ}$ counterclockwise (ccw) from the assumed $\mathrm{N} 45^{\circ} \mathrm{E}$ strike while that due to bipole 2 lies about $70^{\circ}$ clockwise (cw) from strike. That both magnetic fields have stronger $y$ than $x$ components may explain the greater discrepancy exhibited between the yx. scalar and tensor results in light of equation (4). The on-diagonal impedance magnitudes are typically about $30 \%$ of the off-diagonal elements.

At site 24 , the scalar $\rho_{x y}$ due to source 1 is essentially coincident with the tensor $\rho_{x y}$, while the scalar $\rho_{y x}$ due to source 2 is essentially coincident with the tensor $\rho_{y x}$. The other scalar quantities, however, differ by $0.3-0.5 \log$ units. Here, the total magnetic field due to bipole 1 lies about $60^{\circ} \mathrm{ccw}$ from the assumed $N 45^{\circ} \mathrm{E}$ strike while that due to bipole 2 lies about $20^{\circ} \mathrm{cw}$ from strike. In this case, since each bipole's field is close to one of the coordinate directions, the tensorscalar differences are small for the well-coupled components. This suggests that the vector CSAMT measurement discussed in an early section, which measures all fields at a receiver but utilizes only one source bipole, may be sufficient in nearly isotropic areas for resolving a stable response. At site 24, the tensor apparent resistivities $\rho_{x y}$ and $\rho_{y x}$ are isotropic to within $0.05 \mathrm{log}$ units. The on-diagonal impedance magnitudes are typically about $20 \%$ of the off-diagonal elements.

We believe that the resistivity structure of the host rocks containing Valles caldera may be important not only in modeling the plane-wave results at Sulphur Springs but in determining nearfield behavior of the CSAMT source fields. A tensor CSAMT sounding on Schoolhouse Mesa (site SM, Figure 3) is shown in Figure 9 and compared to MT data taken nearby on Lake Mesa (site LM) by G. R. Jiracek. Our sounding overlies about $650 \mathrm{~m}$ of Bandelier Tuff, underlain in turn by the pre-caldera volcanic and Paleozoic sedimentary section and Precambrian basement (Smith et al., 1970). The stratigraphy beneath the CSAMT and MT sites is presumed to be 
essentially equivalent except perhaps at the highest levels due to differing erosion. The agreement between controlled-source and natural field data is again very good over most of the common period range with the exception of a small static offset. The high frequency CSAMT data indicate resistivities of $200-300 \mathrm{ohm}-\mathrm{m}$ in the Bandelier section here, which agrees with well $\log$ information from Wilt and vonder Haar (1986) from inside the caldera but may not be representative of highly fractured and altered tuffs below our survey area.

Transmitter near-field effects appear evident starting around $4 \mathrm{~Hz}$ at site $\mathrm{SM}$ according to discrepancies in the impedance phase especially. The apparent resistivity at this frequency is about $25 \mathrm{ohm}-\mathrm{m}$; if this value serves as an effective medium resistivity then the transmitter would be about six skin depths $(9.5 \mathrm{~km})$ removed from this receiver. This is more in keeping with conventional wisdom about necessary separations to achieve plane-wave responses. The higher apparent resistivities in Figure 9 relative to those in Figure 5 imply that upper crustal structure within the caldera is more conductive than the surrounding host. This may explain the seemingly high frequency at which near-field effects are first noticed at sites around Sulphur Springs, but deserves a finite-source simulation of a 3-D model to quantify. 


\section{FUTURE RESEARCH PLANS}

To analyze the tensor CSAMT method, we propose to use the Sulphur Springs area as a natural laboratory given the extensive, high-quality data set we have gathered there. Defining a resistivity model for the region which includes a detailed component for the Sulphur Springs area, a simplified description of the caldera as a whole, and a 1-D host representing the roughly layered stratigraphy and basement rocks exterior to the caldera, is an essential portion of the analysis. Subsequently, this model will serve as a 3-D structure in a layered host for computer simulation of CSAMT responses and comparison to observed field quantities. The specific plan of procedure is as follows.

\section{Construction of Resistivity Models}

The resistivity model of the host layering to the caldera will be derived primarily from our CSAMT sounding on Schoolhouse Mesa and the nearby natural field MT sounding (Figure 9) but will also consider the dc resistivity data and modeling of Jiracek et al., (1975). We will establish a resistivity profile at SM two ways. First, we will carry out a finite source 1-D inversion of our measurements there which will include the near-field effect explicitly and thus extend the depth of investigation well into the basement. Second, we will carry out a 1-D plane-wave inversion of the combined MT and CSAMT data with the near-field controlled-source data removed. The compatibility of the models, including the dc results, will help verify the assumption of an

effectively 1-D host to the caldera. Joint inversion of MT and the full CSAMT sounding will be attempted as well.

Detailed resistivity sections from the CSAMT data taken along the four profiles shown in Figure 4 are to be derived using 1-D and 2-D resistivity models. The soundings we have taken for the larger part are not very anisotropic; that of Figure 8 is easily in the top 20\% in regard to this. Thus, 1-D plane-wave inversion of the data down to $4 \mathrm{~Hz}$ will serve as a good starting guess for subsequent 2-D modeling. The 2-D models will be constructed using the algorithm described by Wannamaker et al., $(1986,1987)$. Topographic variations along the profiles are substantial and will be included in the 2-D modeling. Resolution in the cross sections will be assessed by perturbing key features and assessing the change in computed response relative to the data (hypothesis testing). However, refinement of these cross sections by incorporation of natural-field MT data or by modeling the controlled-source characteristics can be expected.

We believe that a resistivity model for the caldera as a whole only needs to be approximate to 
demonstrate relative importance of Sulphur Springs structure, the caldera as a whole, and the host to the caldera, with regard to CSAMT field behavior over the Sulphur Springs prospect. The caldera-wide model will be derived primarily from natural-field MT data; sources include Wilt and vonder Haar (1986), stations taken in the SAGE summer program (Figure 3), and donated sites from the Unocal survey. Because we are concerned with structure in just the upper $2-4 \mathrm{~km}$, and data coverage is widely distributed, 1-D interpretation will be emphasized but is considered adequate for this large-scale model. Coverage is sufficient to determine, for example, where the resistivity margin to the caldera lies (i.e., along the ring-fracture system versus the topographic margin). It should be possible to extrapolate average properties of our detailed Sulphur Springs to other portions of the western caldera. For purposes of 3-D simulation of fundamental controlledsource effects, this model could have at least one and perhaps two planes of symmetry.

\section{Controlled-Source Field Geometries at Sulphur Springs}

Decisions regarding transmitter orientation and placement to achieve good source field coupling at receiver sites are typically made on the basis of half-space calculations of EM field geometries (Goldstein and Strangway, 1975; Sandberg and Hohmann, 1982; Zonge and Hughes, 1991). When the field area departs negligibly from a half-space, agreement between observed and theoretical field responses is good (Goldstein and Strangway, 1975). In arbitrary structural environménts, such agreement should not be presumed. As a test of the variability of source geometries in possibly complex areas, we propose to process and examine the raw electric and magnetic fields taken in our survey for comparison to theoretical computations. Field quantities would be presented as polarization ellipses, as we have already utilized in theoretical studies (e.g., Wannamaker et al., 1984). Data statistics of the ellipse parameters will be included.

One component of the theoretical calculations would consider fields over the layered earth derived from data outside the caldera as described above. These field distributions should be compared to those over pure half-spaces whose resistivity equals, e.g., the apparent resistivity of the layering at various frequencies. More important, the uniformity of the theoretical field orientations and amplitudes needs to be compared to the observed cases to establish the importance of local heterogeneity in disturbing these fields. Also, we propose to simulate $\mathrm{E}$ and $\mathrm{H}$ field distributions over the Sulphur Springs portion of the simplified resistivity model of the caldera as a whole in its layered host. This would test the degree to which large-scale inhomogeneity could warp the average field orientation over a survey and affect receiver coupling. The issue is important not only for obtaining strong signal components but in determining the stability of tensor 
versus scalar CSAMT quantities as illustrated with equations (3) and (4) and Figure 8. The 3-D simulations would be carried out using an integral equation algorithm similar to that of Boschetto and Hohmann (1991) but modified to incorporate the improvements of Wannamaker (1991). These include the ability to simulate structures which outcrop, which transect one or more layers of the 1-D host, and which may extend indefinitely in one or more dimensions.

\section{Static Versus Tensor CSAMT Quantities}

The examples of differing tensor versus scalar apparent resistivities in Figure 8 were found without much searching and so it is presumed that the effect is common in the Sulphur Springs data set. We wish to compare scalar and tensor results at all sites in the survey area to characterize completely the degree to which this occurs. Initially, simple histograms of the difference between scalar and tensor $\log \rho_{\mathrm{a}}$ versus frequency of occurrence should be useful. The larger discrepancies need to be correlated with the amount of heterogeneity present (as quantified by the on-diagonal impedance amplitudes) and to the field azimuths relative to the measurement axes. Thus, analyzing the adequacy of scalar results and the orientations of EM fields over the survey area discussed previously are closely tied together. We also wish to compare the vector mode data, which can be constructed from our field results, with the tensor impedance values rotated coincident with the total field azimuths. The data shown in Figure 8 suggested that the vector mode quantities, which are still much more economical to acquire than full tensor data, may agree with the tensor results more closely in general than do the scalar quantities.

\section{Controls on CSAMT Near-Field Behavior}

Near-field effects appear present at the bottom of the frequency range of our data over Sulphur Springs although, given the apparent resistivities typically observed here, it seems somewhat surprising that the effects are present even to the degree that they are. However, this judgement is based on simple half-space considerations and a more rigorous assessment is warranted. Several routes will be pursued. At a number of sites over the survey area which appear close to 1-D (as judged by comparison to the 2-D models and computations), apparent resistivity and phase data will be inverted for 1-D resistivity models using the full finite source assumption. The plane-wave responses of the resulting models will next be computed and compared to the finite source responses. The discrepancy at low frequencies between these two types of responses will be compared to the discrepancy observed between CSAMT data and the MT data at corehole VC-2B 
and at Sulphur Point and Redondo Border (Figures 4 and 5). If the apparent near-field effects are essentially the same, then it may be concluded that structure local to the Sulphur Springs area is most important.

A similar analysis will have been made over the layered host to the caldera in the course of finite source inversion of the CSAMT data on Schoolhouse Mesa and comparison to nearby MT results (Figure 9) to determine the host parameters. We expect that this layering will determine the nearfield effect here because the layering represents most of the medium between the source and receiver at site SM (Figure 3). Subsequently, the controlled-source $\rho_{\mathrm{a}}$ and phase at our survey area (i.e., VC-2B) due to the layered host will be determined and compared to the plane-wave layering response and to representative soundings. Finally, near-field effects will be assessed by a 3-D simulation of the simplified whole-caldera model in its 1-D host using the integral equations code. This model will computed both for our finite source configuration and for plane waves, and responses compared over the Sulphur Springs area. In reality, it is expected that this latter simulation will be the most rigorous and provide the best explanation of near-field behavior in our survey, but in the course of the study we will have evaluated the contributions of end member components of the total resistivity structure. The 3-D study should demonstrate also whether inhomogeneity distortions are similar for both plane-wave and finite source responses, which is important if near-field correction schemes based on a 1-D assumption are to be useful. We hope as well that such modeling will extend the depth of exploration in the area through at least a semiquantitative modeling of the controlled-source results at the longest periods. 


\section{REFERENCES}

Aldrich, M. J., Jr., Tectonics of the Jemez Lineament in the Jemez Mountains and Rio Grande Rift, J. Geophys. Res., 91, 1753-1762, 1986.

Bartel, L. C., and R. D. Jacobson, Results of a controlled-source audiofrequency magnetotelluric survey at the Puhimau thermal area, Kilauea Volcano, Hawaii, Geophysics, 52, 665-677, 1987.

Bevington, P. R., Data reduction and error analysis for the physical sciences, McGraw-Hill Book Co., New York, 336 pp., 1969.

Boschetto, N. B., and G. W. Hohmann, Controlled-source audiofrequency magnetotelluric responses of three-dimensional bodies, Geophysics, 56, 255-264, 1991.

Bostick, F. X., Jr., Electromagnetic array profiling (EMAP), expanded abstract, Soc. Explor. Geophys. 56th Ann. Mtg., Houston, Tex., 1986.

Corbett, J. D., Overview of geophysical methods applied to precious metal exploration in Nevada, in Geology and ore deposits of the Great Basin, ed. by G. L Raines, R. E. Lisle, R. W. Schafer, and W. H. Wilkinson, Geological Society of Nevada, vol. II, 1237-1251, 1991.

Crecraft, H., G. Nordquist, B. M. Smith, and R. J. Varga, Evidence for geothermal upflow within the eastern half of the Valles caldera, northern New Mexico, EOS Trans., AGU, 69, 1481, 1988.

deGroot-Hedlin, C., and S. C. Constable, Occam's inversion to generate smooth, twodimensional models from magnetotelluric data, Geophysics, 55, 1613-1624, 1990.

Gamble, T. D., W. M. Goubau, and J. Clarke, Error analysis for remote reference magnetotellurics, Geophysics, 44, 959-968, 1979.

Goldstein, M. A., and D. W. Strangway, Audio-frequency magnetotellurics with a grounded electric dipole source, Geophysics, 40, 669-683, 1975.

Goff, F. E., and J. N. Gardner, Geologic map of the Sulphur Springs geothermal system, Valles caldera, New Mexico, Los Alamos Scientific Laboratory Map, LA-8634-MAP, 2 sheets, 1980.

Goff, F., J. Gardner, R. Vidale, and R. Charles, Geochemistry and isotopes of fluids from Sulphur Springs, Valles caldera, New Mexico, J. Volcan. Geotherm. Res., 23, 273-297, 1985.

Goff, F., L. Shevenell, J. N. Gardner, F.-D. Vuataz, and C. O. Grigsby, The hydrothermal outflow plume of Valles caldera, New Mexico, and a comparison with other outflow plumes, J. Geophys. Res., 93, 6041-6058, 1988.

Heiken, G., F. Goff, J. N. Gardner, W. S. Baldridge, J. B. Hulen, D. L. Nielson, and D. Vaniman, The Valles/Toledo caldera complex, Jemez volcanic field, New Mexico, Annu. Rev. Earth Planet. Sci., 18, 27-53, 1990.

Hughes, L. J., and N. R. Carlson, Structure mapping at Trap Springs Oilfield, Nevada, using controlled-source magnetotellurics, First Break, 5, 403-418, 1987. 
Hulen, J. B., and D. L. Nielson; 1986a, Stratigraphy and hydrothermal alteration in well Baca-8, Sulphur Springs area, Valles caldera, New Mexico, Geothermal Resources Council Trans., 10, 187-192, 1986a.

Hulen, J. B., and D. L. Nielson, 1986b, Hydrothermal alteration in the Baca geothermal system, Redondo Dome, Valles caldera, New Mexico, J. Geophys. Res., 91, 1967-1986, $1986 \mathrm{~b}$.

Hulen, J. B., and J. N. Gardner, Field geologic log for CSDP corehole VC-2B, Valles caldera, New Mexico, Rep. ESL-89025-TR, 92 pp., Univ. of Utah Res. Inst, Salt Lake City, 1989.

Hulen, J. B., D. L. Nielson, F. Goff, J. N. Gardner, and R. W. Charles, Molybdenum mineralization in an active geothermal system, Valles caldera, New Mexico, Geology, 15, 748 $752,1987$.

Hulen; J. B., J. N. Gardner, D. L. Nielsón, and F. Goff, Stratigraphy; structure, hydrothermal mineralization, and ore mineralization encountered in CSDP corehole VC-2A, Sulphur Springs. area, Valles caldera, New Mexico - a detailed overview, Rep. ESL-88001-TR, 55 pp., Univ. of Utah Res. Inst., Salt Lake City, 1988.

Hulen, J. B., D. L. Nielson, and T. M. Little, Evolution of the western Valles caldera complex, New Mexico: evidence from intracaldera sandstones, breccias, and surge deposits, J. Geophys. Res.; 96, 8127-8142, 1991.

Jiracek, G. R., C. Smith, and G. A. Dorn, Deep geothermal exploration in New Mexico using electrical resistivity, in Proc. Second United Nations Symp. on the Devel. and Use of Geothermal Resources, v. 2, 1095-1103, 1975.

Jiracek, G. R., W. S. Baldridge, and L. J. Hix, SAGE - A unique geophysical experience, The Leading Edge, Soc. Explor. Geophys., 45-49, March, 1991.

Keller, G. V., Rock and mineral properties, in Electromagnetic Methods in Applied Geophysics, edited by M. N. Nabighian; Soc. Explor. Geophys., Tulsa, Okla., 13-52, 1988.

Nielson, D. L., and J. B. Hulen, Internal geology and evolution of Redondo Dome, Valles caldera, New Mexico, J. Geophys. Res., 89, 8695-8711, 1984.

Olhoeft, G., Electrical properties of rocks, in Physical properties of rocks and minerals, ed. by Y. S. Touloukian and C. Y. Ho, McGraw-HillCINDAS Data Series on Material Properties, II-2, New York, 257-297, 1981.

Ostrander, A. G., Structural mapping at the Tomera Ranich oil field using CSAMT: a case history, Nevada Petroleum Society Fieldtrip Guidebook, 57-68, 1990.

Quist, A. S., and W. L. Marshall, The electrical conductances of aqueous sodium chloride solutions from 0 to $800 \mathrm{C}$ and at pressures to 4000 bars, J. Phys. Chem., 71, 684-703, 1968.

Sandberg, S. K., and G. W. Hohmann, Controlled-source audiomagnetotellurics in geothermal exploration, Geophysics, 47, 100-116, 1982.

Smith, J. T., and J. R. Booker, Rapid inversion of two- and three-dimensional magnetotelluric data, J. Geophys. Res., 96, 3905-3922, 1991. 
Smith, R. L., and R. A. Bailey, Resurgent cauldrons, in Studies in volcanology, ed. by R. R. Coats, R. L. Hay, and C. A. Anderson, Mem. Geol. Soc. Am., 116, 613-662, 1968.

Smith, R. L., R. A. Bailey, and C. S. Ross, Geologic map of the Jemez Mountains, New Mexico, U. S. Geol. Surv., Misc. Geol. Invest., Map I-571, 1970.

Stodt, J. A., Noise analysis for conventional and remote reference magnetotellurics, $\mathrm{Ph} . \mathrm{D}$. thesis, University of Utah, Salt Lake City, 220 pp., 1983.

Torres-Verdin, C., and F. X. Bostick, Jr., Principles of spatial surface electric field filtering in magnetotellurics: electro-magnetic array profiling (EMAP), Geophysics, in press, 1991.

Vozoff, K., ed., Magnetotelluric methods, Geophys. Reprint Ser., vol. 5, Soc. Explor. Geophys., Tulsa, Okla., 800 pp., 1986.

Wannamaker, P. E., Resistivity structure of the Northern Basin and Range, in The role of heat in the development of energy and mineral resources in the Northern Basin and Range, Geothermal Resouces Council Spec. Rep. 13, 345-363, 1983.

Wannamaker, P. E., Advances in three-dimensional magnetotelluric modeling using integral equations, Geophysics, 56, Nov., 1991, in press.

Wannamaker, P. E., G. W. Hohmann, and S. H. Ward, Magnetotelluric responses of threedimensional bodies in layered earths, Geophysics, 49, 1517-1533, 1984.

Wannamaker, P. E., J. A. Stodt, and L. Rijo, Two-dimensional topographic responses in magnetotellurics modeled using finite elements, Geophysics, 51, 2131-2144, 1986.

Wannamaker, P. E., J. A. Stodt, and L. Rijo, A stable finite element solution for two-dimensional magnetotelluric modeling, Geophys. J. Roy. Astr. Soc., 88, 277-296, 1987.

Wannamaker, P. E., J. R. Booker, A. G. Jones, A. D. Chave, J. H. Filloux, H. S. Waff, and L. K. Law, Resistivity cross section through the Juan de Fuca subduction system and its tectonic implications, J. Geophys. Res., 94, 14,127-14,144, 1989.

Wannamaker, P. E., P. M. Wright, Z.-X. Zhou, X.-B. Li, and J.-X. Zhao, Magnetotelluric transect of Long Valley caldera: resis- tivity cross section, structural implications, and the limits of a two-dimensional analysis, Geophysics, 56, 926-940 1991.

Wannamaker, P. E., and G. W. Hohmann, Electromagnetic induction studies, U. S. National Rep. to IUGG, Rev. Geophys., Supplement, 405-415, 1991.

Ward, S. H., W. T. Parry, W. P. Nash, W. R. Sill, K. L. Cook, R. B. Smith, D. S. Chapman, F. H. Brown, J. A. Whelan and J. R. Bowman, A summary of the geology, geochemistry and geophysics of the Roosevelt Hot Springs thermal area, Utah, Geophysics, 43, 1515-1542, 1978.

Ward, S. H., and W. R. Sill, Dipole-dipole resistivity surveys, Roosevelt Hot Springs KGRA, NSF Technical Rep., 76-2, Univ. of Utah, 29 pp., 1976. 
Waxman, M. H., and L.T.M. Smits, Electrical conductivities in oil-bearing shaly sands, Trans Soc. Pet. Eng., 243, 107-123, 1968.

Wilds, S. R., and S. MacInnes, High resolution CSAMT applications in gold exploration - a case history, in Geology and ore deposits of the Great Basin, ed. by G. L. Raines, R. E. Lisle, R. W. Schafer, and W. H. Wilkinson, Geological Society of Nevada, vol. II, 1231-1236, 1991.

Wilt, M., and S. vonder Haar, A geological and geophysical appraisal of the Baca geothermál field, Valles caldera, New Mexico, J. Volcan. Geotherm. Res., 27, 349-370, 1986.

Zohdy, A. A. R., L. A. Anderson, and L. J. P. Muffler, Résistivity, self-potential, and induced polarization surveys of a vapor-dominated geothermal system, Geophysics, 38, 1130-1144, 1973.

Zonge, K. L., and L. J. Hughes, Controlled source audiomagnetotellurics, in Electromagnetic methods in applied geophysics, vol. 2, Practice, ed. by M. N. Nabighian, Soc. Explor. Geophys., 1991 , in press.

Zonge, K. L., A. G. Ostrander, and D. F. Emer, Controlled source audio-frequency magnetotelluric measurements, in Magnetotelluric methods, ed. by K. Vozoff, Soc. Explor. Geophys., 749-763, 1986. 


\section{FIGURES}

1. Comparison of scalar and tensor CSAMT measurement setups (redrawn from Zonge and Hughes, 1991). For the scalar approach, the broadside configuration is shown where source and electric field sensors are parallel and the electric field is measured along the profile. For the tensor approach, the coincident source configuration is shown as it is logistically the most feasible and was undertaken at Sulphur Springs.

2. Example far-field through near-field CSAMT responses over a uniform half-space (top) and a four-layered earth (bottom). The layered earth section may be roughly representative of that at Sulphur Springs, but scaled down in dimensions by a factor of five (i.e., frequency response shifted upward by 25). Redrawn from Zonge and Hughes (1991).

3. Regional geological map of Valles caldera showing principal geological features and survey layout. Crossed-bipole transmitter antennae are about $13 \mathrm{~km} \mathrm{SSW}$ of corehole VC-2B and Sulphur Springs (SS). CSAMT data was taken outside caldera on Schoolhouse Mesa (SM) and natural field MT data taken on Lake Mesa (LM). Other MT sites taken in SAGE program drawn with $L$ sysmbols and available from Unocal Co. drawn with diamonds. Fenton Hill hot dry rock prospect is FH and resurgent dome of Redondo Peak is RP. Geology primarily after Smith et al., (1970) and Hulen et al., (1991).

4. Detailed geology and CSAMT survey layout of Sulphur Springs area. Data was taken in four profiles designed to cross major structural features. Dots denote electrode positions (i.e., bipole spans along the profiles). Bipoles normal to profiles not drawn but were all $250 \mathrm{~m}$ in length. Stippling and labels same as for regional map. Geology after Goff and Gardner (1980) and Hulen et al., (1991).

5. Tensor CSAMT data taken about $125 \mathrm{~m} \mathrm{SE}$ of VC-2B compared to natural field MT data taken by G. R. Jiracek. Error intervals are nominally two standard deviations. Near-field effects in CSAMT results appear to occur at 1 and $2 \mathrm{~Hz}$ especially in the phase. The $\mathrm{x}$-axis is $\mathrm{N} 45^{\circ} \mathrm{E}$ and $\mathrm{y}$-axis is $S 45^{\circ} \mathrm{E}$ for all periods.

6. Pseudosections of nominal TE ( $x y$-mode, top) and TM (yx-mode, bottom) apparent resistivity and impedance phase for central line N1 crossing VC-2B corehole. Contour intervals are $0.2 \log$ units in $\rho_{\mathrm{a}}$ and $5^{\circ}$ in phase. Contours are plotted from endpoint to endpoint of the profile and are based hand-smoothed sounding values.

7. Pseudosections of complex tipper elements $M_{z y}$ (TE mode, top) and $M_{z x}$ (bottom) for central line N1 crossing VC-2B corehole. Contour intervals are 5\% for all quantities. Dashed contours denote negative values. Contours are plotted from endpoint to endpoint of the profile and are based hand-smoothed sounding values.

8. Example soundings comparing scalar and tensor apparent resistivities at two sites on line N1. Upper panels show xy quantities while lower panels show yx. Scalar results are shown with box symbols plus error bars while tensor results are shown as error intervals only. At site 24, tensor results are nearly coincident with lower scalar data (tensor errors seen protruding below solid scalar symbols). Transmitter bipole number giving rise to each scalar curve is denote 1 or 2 .

9. Tensor CSAMT data taken on Schoolhouse Mesa compared to natural field MT data taken by G. R. Jiracek. Error intervals are nominally two standard deviations. Near-field effects in CSAMT results appear to occur below and including $4 \mathrm{~Hz}$, especially in the phase. The $\mathrm{x}$-axis is $\mathrm{N} 45^{\circ} \mathrm{E}$ and $\mathrm{y}$-axis is $\mathrm{S} 45^{\circ} \mathrm{E}$ for all periods. 
a) Scalar CSAMT, Broadside Configuration

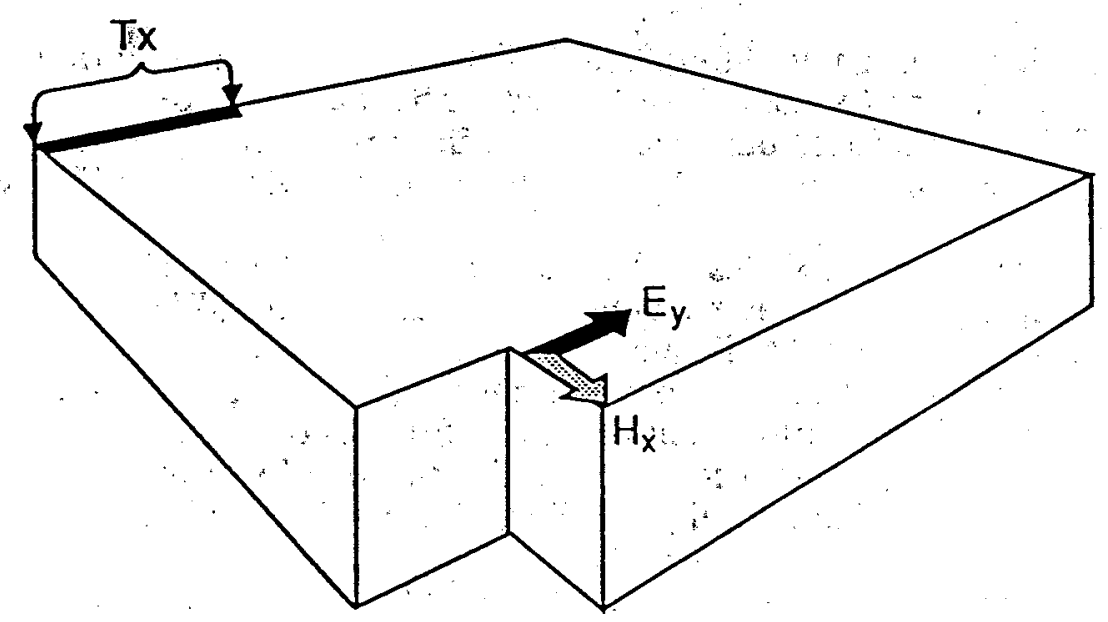

b) Tensor CSAMT, Coincident Sources

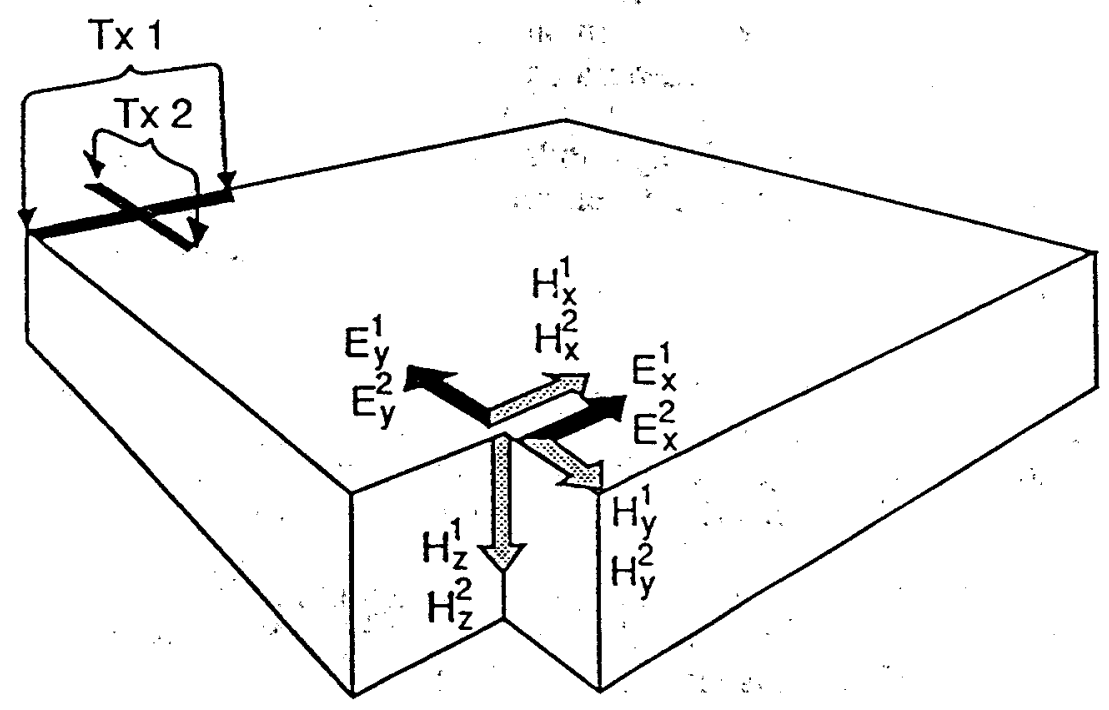



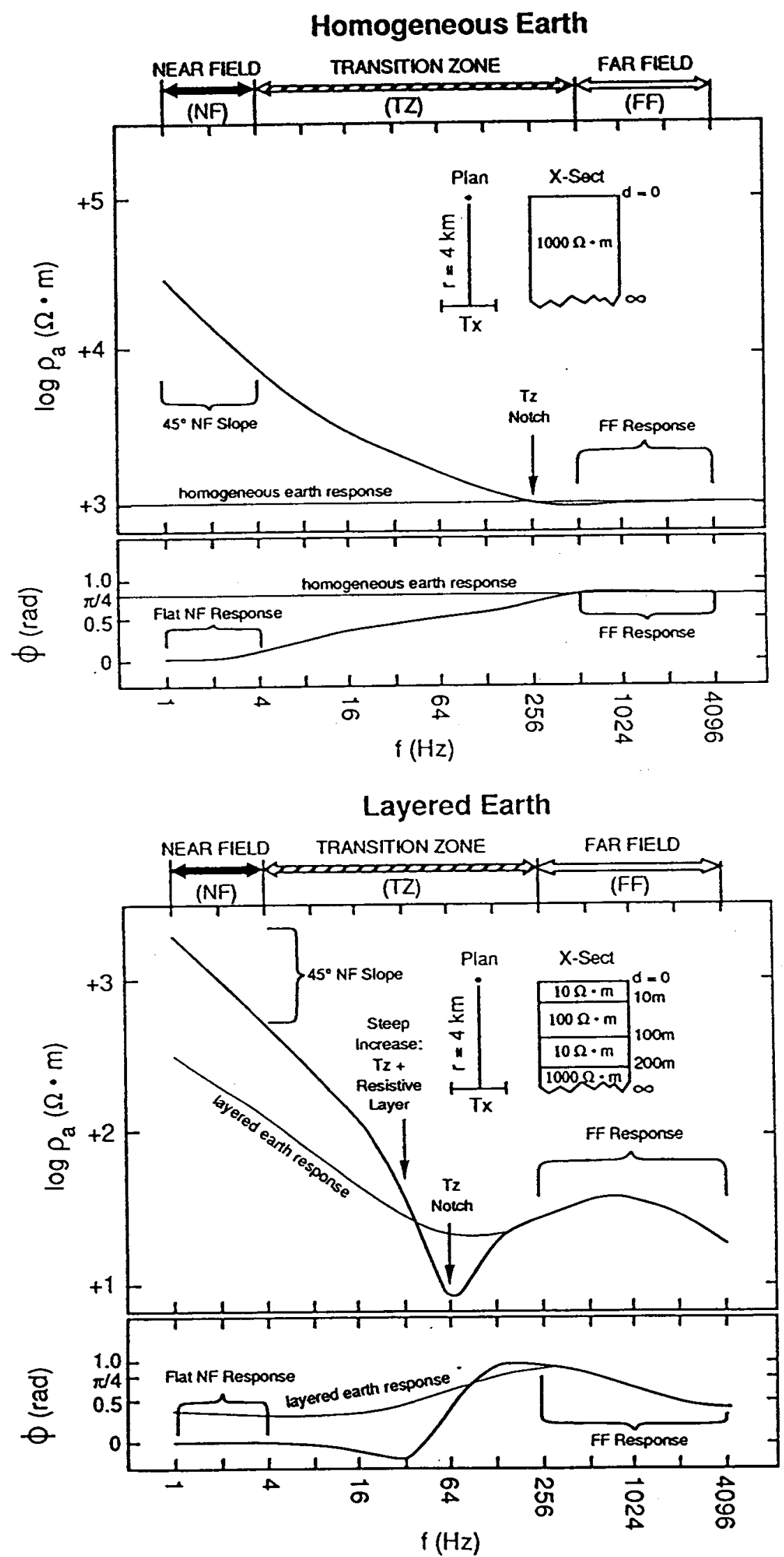

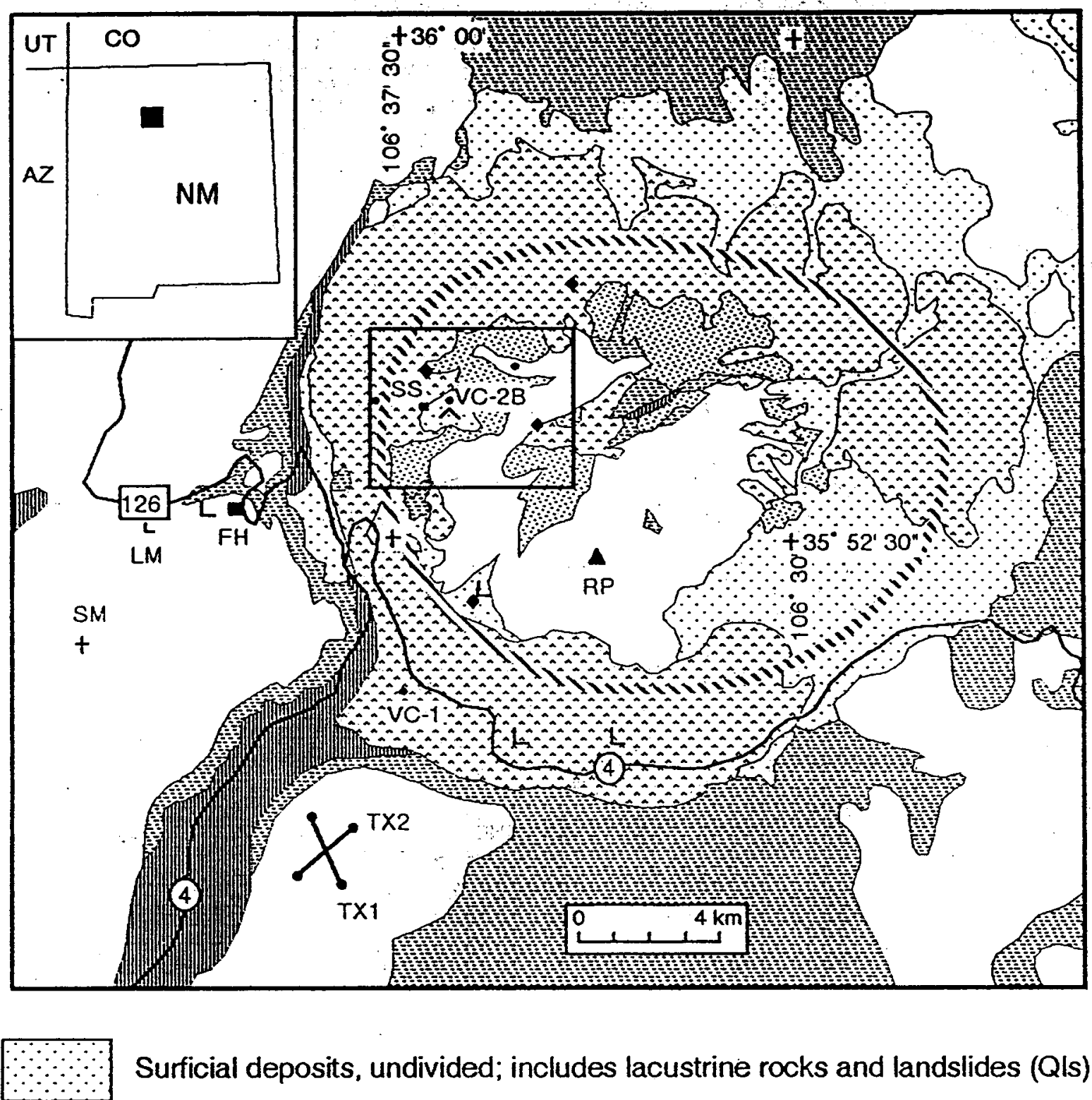

Surficial deposits, undivided; includes lacustrine rocks and landslides (QIs)

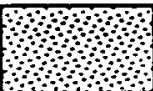

Caldera-fill deposits (Pleistocene); unsorted rock debris from slumping or venting

$\hat{\therefore} \hat{\hat{\prime}} \hat{\circ}$ Valles Rhyolite; includes ring-fracture domes, flows, and tuffs (Qvv); may include resurgent dome units (Qvrc)

Bandelier Tuff and associated ignimbrites

Pre-Valles caldera volcanics (Miocene-Pliocene)

Penn.-Perm. siliciclastic and carbonate rocks 

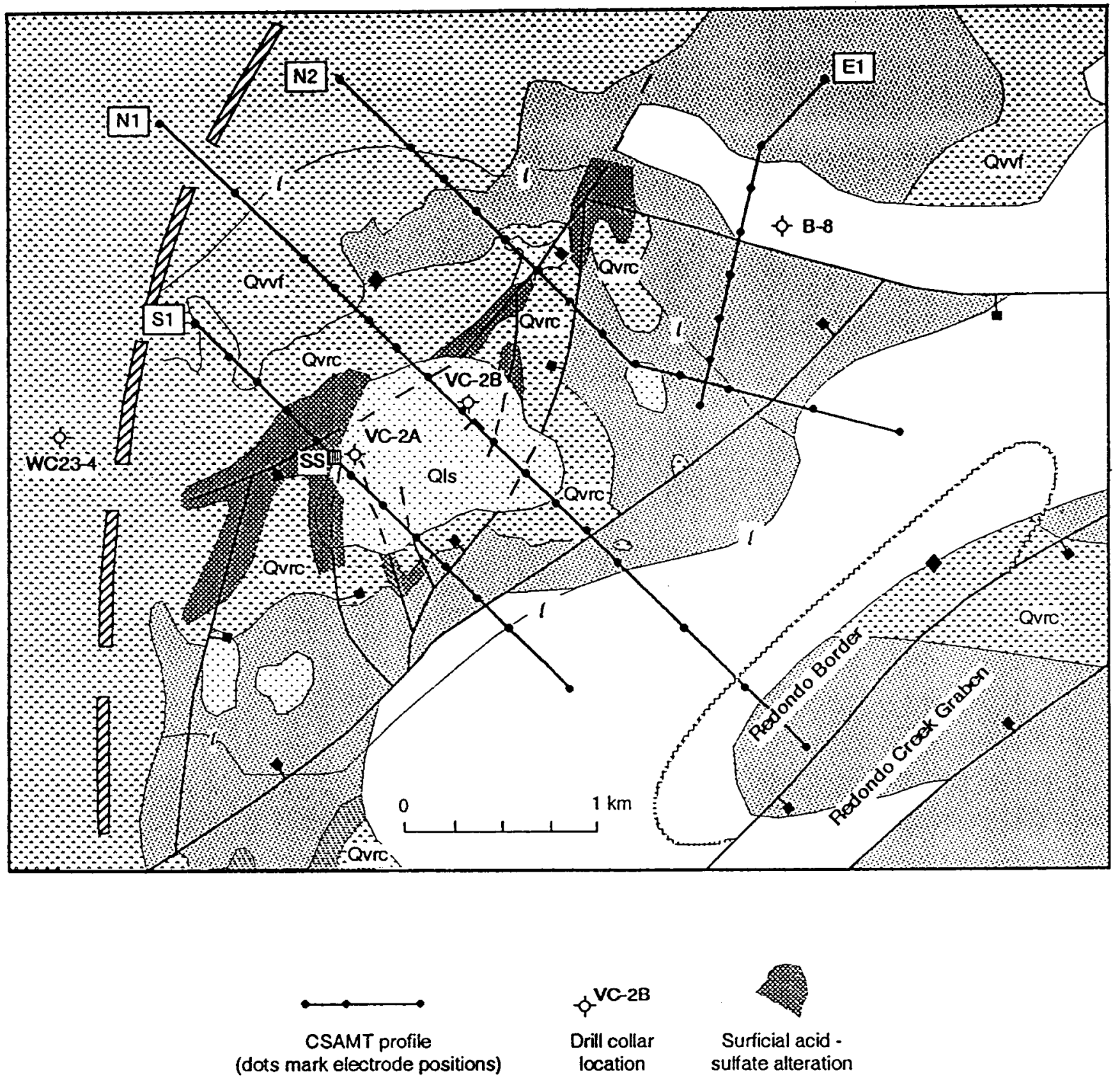

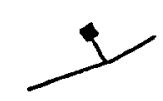

Fault, square on down-thrown side

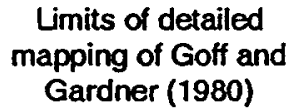

Limits of detailed

Gardner (1980)

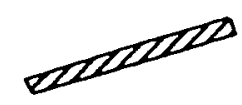

Caldera structural

margin (ring-fracture system)

Stippling as for regional map 


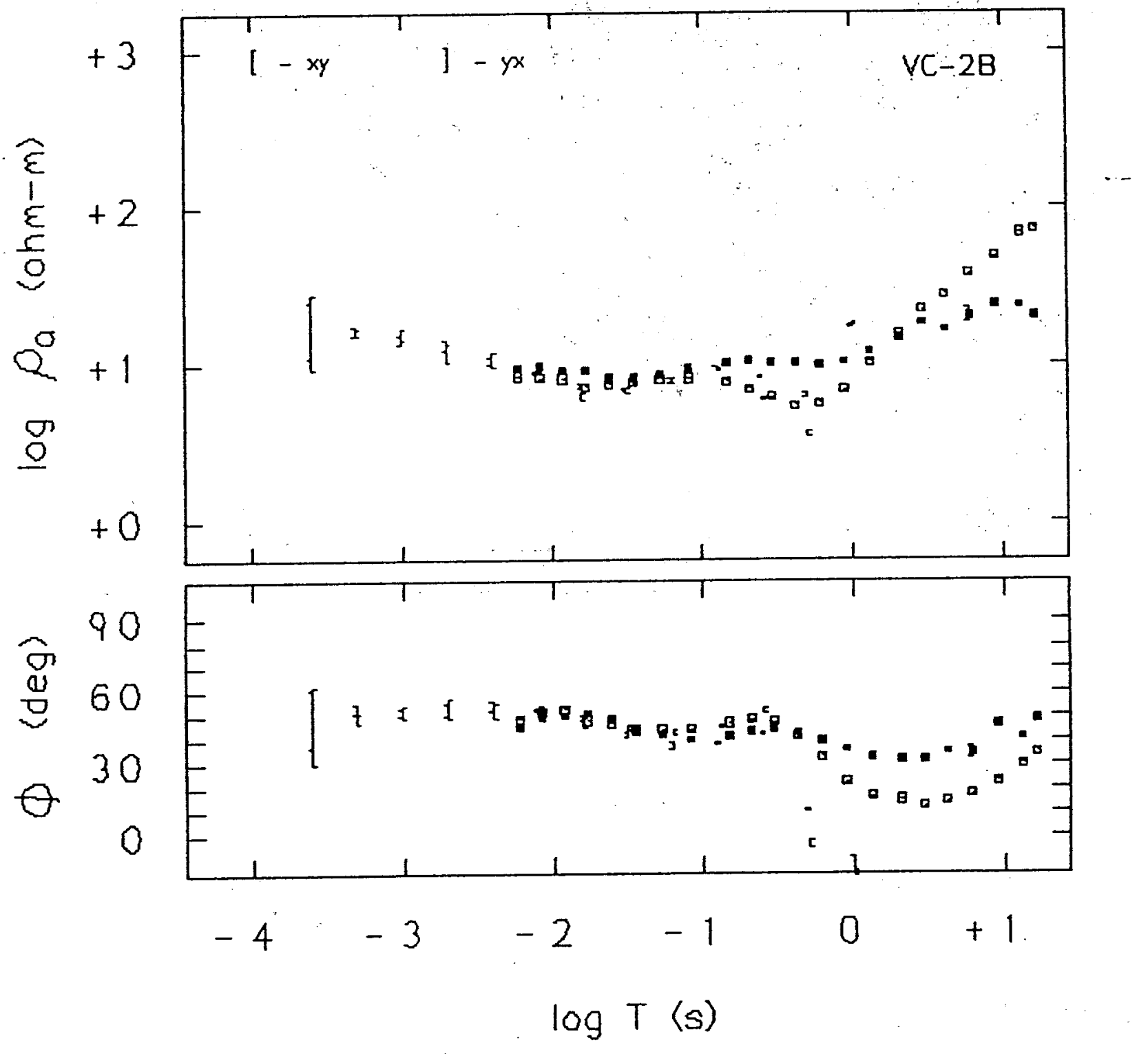



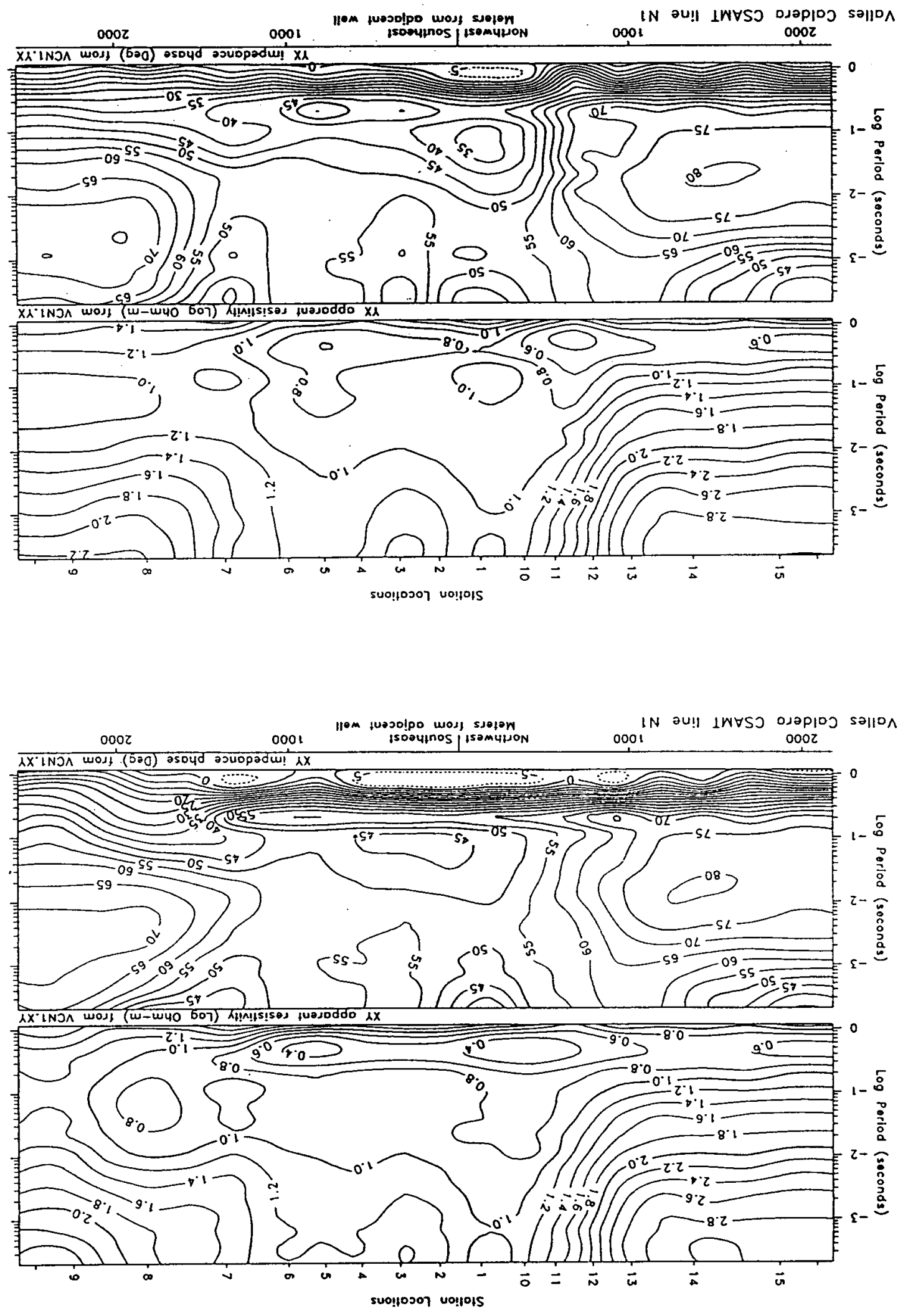

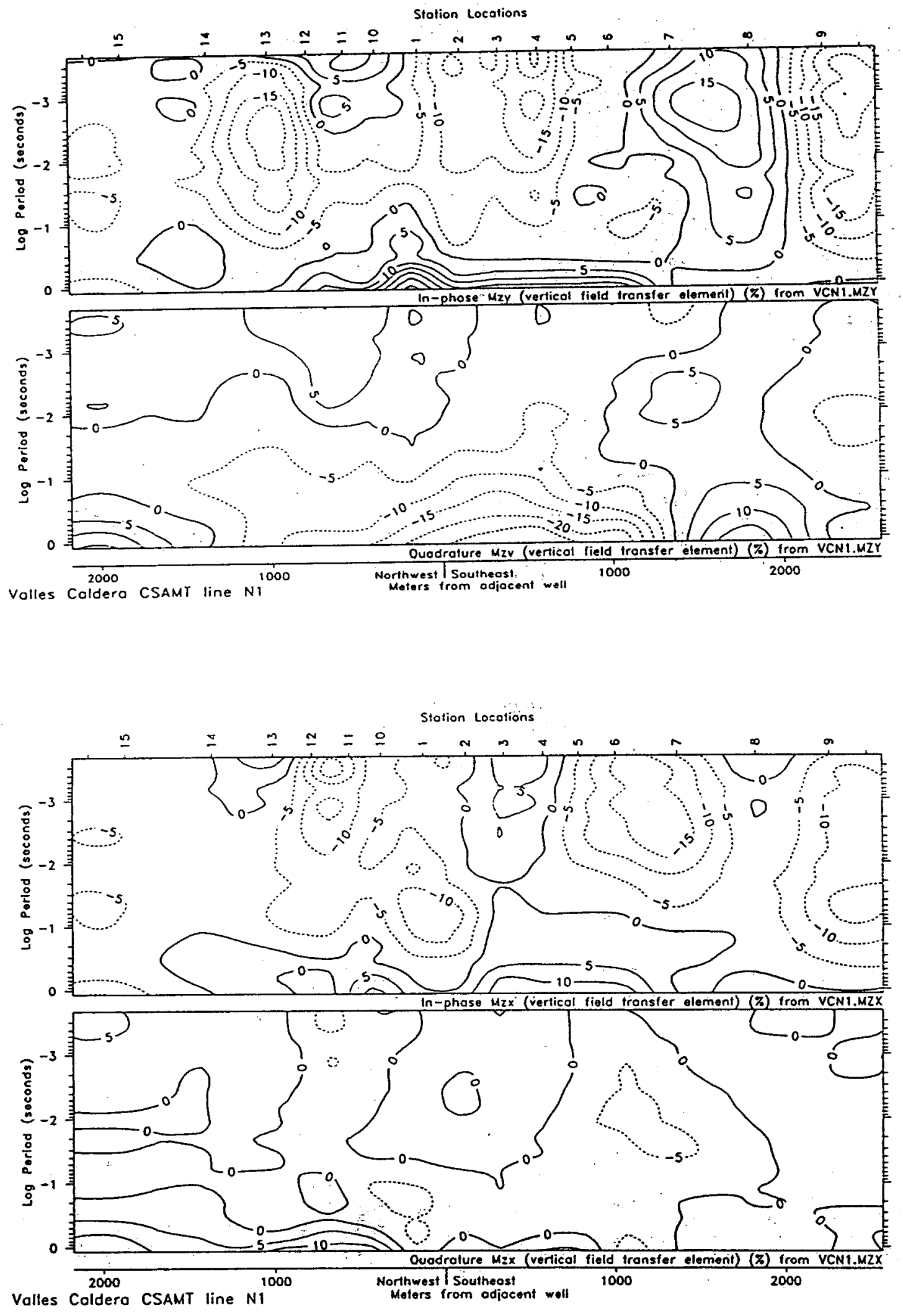

7. 

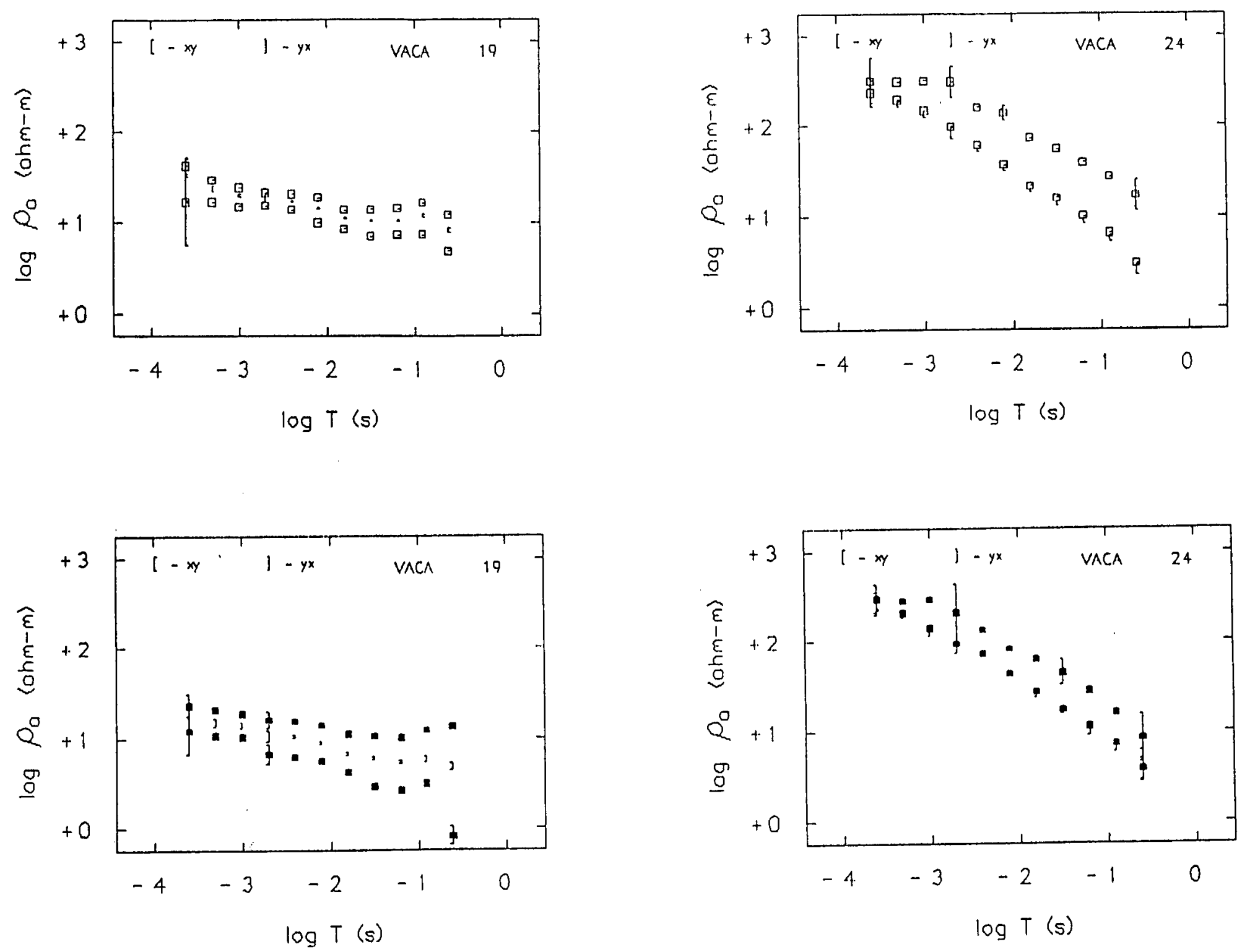

8. 


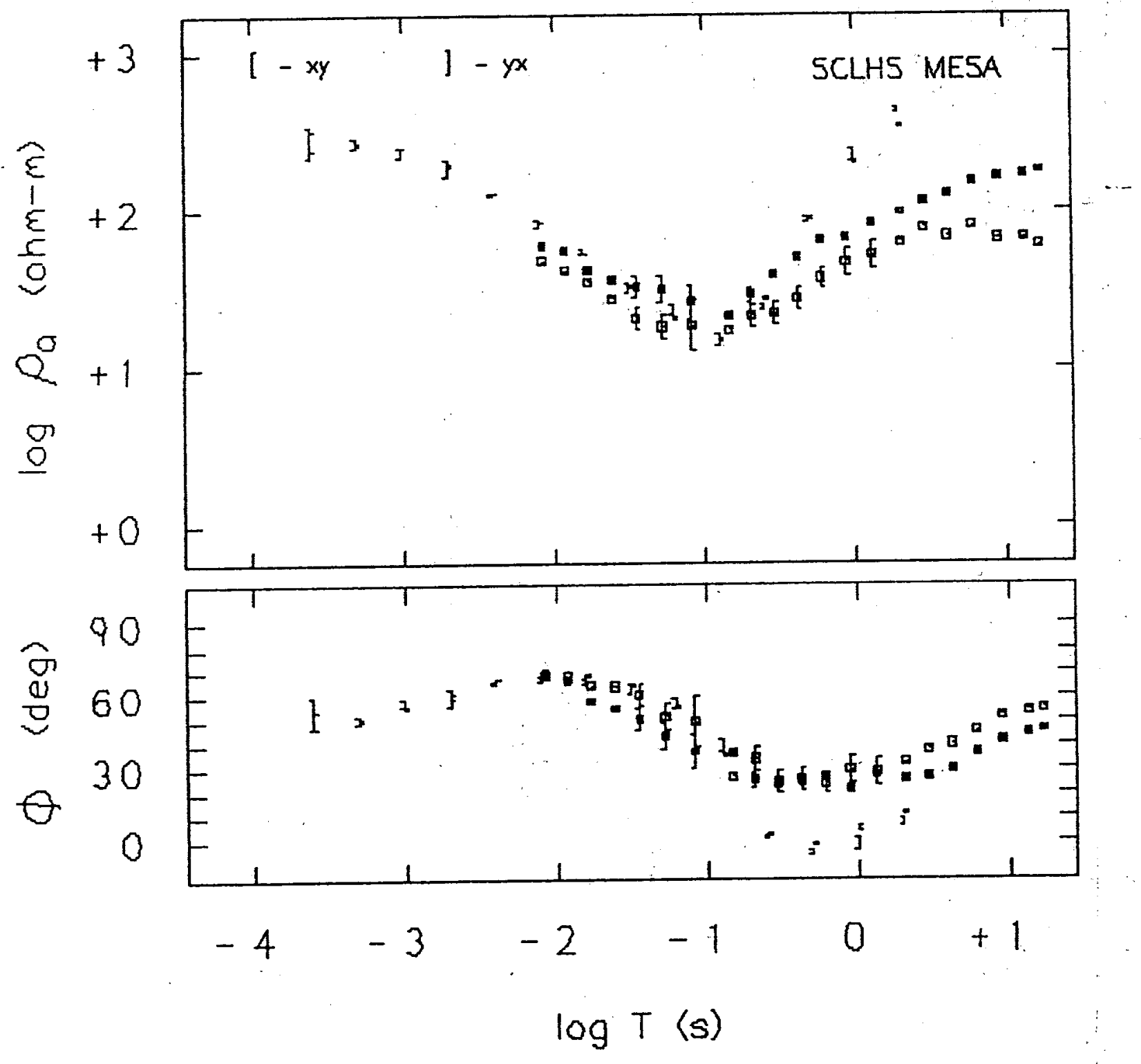

